\title{
EFFECT OF INFECTION CONTROL PROGRAM ON CATHETER ASSOCIATED URINARY TRACT INFECTION IN INTENSIVE CARE UNITS AT ZAGAZIG UNIVERSITY HOSPITAL
}

\author{
Seham Mahmoud Selim*, Amany Rashad Abo El-Seoud, Abd Allah Hasan Mohamed, Salah \\ Abd Al-Rahman Ibrahim \\ Community, Environmental and Occupational Medicine Department, Faculty of medicine, Zagazig \\ University, Egypt
}

\begin{abstract}
Background: Catheter-associated urinary tract infection produces substantial morbidity in hospitalized patients including discomfort, fever, malaise and unnecessary antibiotic use, which may become an important source of antibiotic resistant organisms. Further, the catheterized urinary tract acts as a reservoir for the dissemination of these drug resistant organisms to other patients.

Aim of the study: was to improve the safety of intensive care unit (ICU) patients with urinary catheter via decreasing the incidence of catheter-associated urinary tract infection (CAUTI) at Zagazig University Hospital through assessment of knowledge and practice of ICU staff about catheter associated infection and assessment of the incidence of CAUTI among ICU patients in Zagazig University Hospital and implementation of Infection Control Program in the selected ICUs.

Subjects and methods: An interventional study (one-group pre-test post-test design) was conducted during the period from 2016 to 2018 at Zagazig university Hospital in two ICUs; surgical and emergency intensive care units. The study was carried out through two phases; the first included the followings: active electronic surveillance for (CAUTI); assessment of health care providers' knowledge about CAUTI before and after intervention through constructed questionnaire and assessment of health care providers' practice before and after intervention by using performance observation checklist. The second phase, included implementation of infection control program based on the conceptual model of Comprehensive Unit-based Safety Program (CUSP).

Results: There was a high statistical significant increase in knowledge of resident physicians and nurses about guidelines for prevention of catheter associated urinary tract infection in the studied intensive care units after intervention $(\mathrm{P}<0.01)$. There was high statistical significant improvement in urinary catheterization practice in the studied intensive care units after intervention $(\mathrm{P}<0.01)$. Regarding incidence of CAUTI, before intervention, CAUTI incidence was 10.6 per 1000 urinary catheter days. After intervention, CAUTI incidence significantly dropped to 5.4 per 1000 urinary catheter days. Risk of CAUTI before intervention was approximately twice that after intervention. The intervention reduced risk of CAUTI by $49.1 \%$. Regarding isolated pathogens associated with reported CAUTI, the most frequent isolated pathogens were Klebsiella spp. (31.4\%), followed by Candida albicans (21.4\%), Pseudomonas spp. (14.3\%) and E. coli (12.9\%)

Conclusion: At Zagazig university hospitals' ICUs, implementation of infection control program on CAUTI was noticed to be associated with improvement in healthcare providers' knowledge and practice and decrease in CAUTI incidence. Sustainability is required to maintain such improvement. So. It is recommended to keep continuous training of ICU staff and upgrade ICU protocols according to recent guidelines.
\end{abstract}

Keywords: Infection Control, Catheter Associated Urinary Tract Infection, Intensive Care Units

*Corresponding author: Telephone: 01226259145; Email: seham.eldeeb86@gmail.com

\section{INTRODUCTION}

H ealthcare-associated infections (HAIs) are infections that patients acquire during the course of receiving treatment for other conditions within a healthcare setting and are not present or incubating at the time of admission (1). Medical instrumentation increases the risk of development of HAIs and most patients admitted for health care are exposed to some kind of medical device in the course of their treatment. Such devices include, but are not limited to, venous and urinary catheters, and ventilators (2).

Catheter-associated urinary tract infection (CAUTI) is defined as a urinary tract infection that occurs in persons with an indwelling urinary catheter. A urinary tract infection (UTI) is an inflammatory response of the epithelium of the urinary tract to invasion and colonization by pathogen, 
usually a bacterial species (3). CAUTIs are classified as a complicated UTI and the most common cause of health care-associated infection (4).

During hospitalization, from $10 \%$ to $25 \%$ of patients may receive indwelling urinary catheters, of whom $20 \%$ suffer from urinary tract infection. The daily risk of acquisition of urinary infection varies from $3 \%$ to $7 \%$ when an indwelling urinary catheter remains in place. $50 \%$ of patients are infected after 15 days of installation of the catheter, and almost $100 \%$ of them are infected after one month (5).

In Egypt, Urinary tract infections (UTIs) are one of the most common types of healthcare associated infection (HAI) and deviceassociated infections. Majority of healthcareassociated UTIs are caused by instrumentation of the urinary tract. Catheterassociated urinary tract infection (CAUTI) has been associated with increased morbidity, mortality, hospital cost, and length of stay. In Zagazig university hospitals, the problem of CAUTI has not been searched from public health standpoint yet. Infection control unit looks at CAUTI as one of its top priorities in ICUs field.

In 2015 the Agency for Healthcare Research and Quality (AHRQ) lunched the Comprehensive Unit-based Safety Program (CUSP) to prevent CAUTI. This project combines the implementation of general socio-adaptive approaches to improve care in a particular unit or hospital coupled with evidence-based interventions focusing on the technical aspects of CAUTI prevention (6).

CUSP is a five-step program designed to change a unit's workplace culture to bring about significant safety improvement through empowering staff to assume responsibility for safety in their environment. This is achieved through education, awareness, access to organization resources, and a toolkit of interventions (6).

This study aimed to improve the safety of ICU patients with urinary catheter via decreasing the incidence of CAUTI at Zagazig University Hospital through assessment of knowledge and practice of ICU staff about catheter associated infection and assessment of the incidence of CAUTI among
ICU patients in Zagazig University Hospital and implementation of Infection Control Program in the selected ICUs.

\section{SUBJECTS AND METHODS}

Type of study: An interventional study (Onegroup pre-test post-test design).

Study setting: This study was conducted during the period from 2016 to 2018 at Zagazig university Hospital in two ICUs; surgical ICU and emergency ICU.

Target population: All patients with urinary catheter admitted in both ICUs during the period of study were consecutively enrolled in the study (355 patients before intervention and 319 patients after intervention) and health care providers (resident physicians and nurses) who were working in the studied units and involved in insertion, maintenance and care of urinary catheter during the period of study were included in the study during the period of study were included in the study.

Sample size: Assuming that percentage of health care providers with adequate knowledge about CAUTI prevention guidelines before intervention is $40 \%$, after intervention $75 \%$ (7), at confidence level $95 \%$ and power $80 \%$, so total sample size is 70 health care providers. Calculated by Epi Info 7 version 7.2.0.1 (8).

Sample technique: Zagazig university Hospital which has 13 ICUs: Cardiac (2 ICUs), Respiratory (1 ICU), Neurologic (1 ICU), General medical (1 ICU), Stroke care (1 ICU), GIT (2 ICUs), Pediatric (1 ICU), Neonatal (2 ICUs), Surgical (1 ICU), Emergency (1 ICU). Two of these ICUs were selected; surgical intensive care unit (15 beds) and emergency intensive care unit (15 beds). The selected two units fulfilled the following criteria:

- Have high percentage of urinary catheter utilization.

- Patients admitted for duration suitable for acquiring catheter associated urinary tract infection (low bed turnover rate).

- Have enough number of resident physicians and nurses that satisfy the required sample size

- Have high risk of CAUTI (9). 
Data collection: It was done through two phases:

First phase (pre- intervention) included the following:

Active electronic surveillance for catheter associated urinary tract infection (CAUTI) with technical and financial support of from the U.S. Centers for Disease Control and Prevention's (CDC's) Global Disease Detection (GDD) Program in Egypt, the U.S. Naval Medical Research Unit (NAMRU-3), and the U.S. Agency for International Development (USAID). Personal digital assistants (PDAs) were used to facilitate data entry. The PDAs were programmed using a decision-based tree to help with classifications of HAIs based on CDC/NHSN surveillance criteria. Only suspected cases were entered into PDAs.

Assessment of health care providers' knowledge about CAUTI through constructed questionnaire prepared by the researcher about the following areas: Demographic characteristics of health care providers in studied ICUs (age, qualification, duration of experience in ICU, attending training courses on infection control). Knowledge about Infection control inside ICUs, CAUTI \& its prevention, Guidelines for urinary catheterization, Guidelines for urinary catheter and perineal care and Guidelines for urine bag and drainage system care.

Assessment of health care providers' practice by Performance observation checklist prepared by researcher according to Association for Professionals in Infection Control and Epidemiology (APIC) Implementation Guide, 2014 (10) which include items about the following procedures: Aseptic technique for urinary catheter insertion, Urinary catheter and perineal care technique, Urine bag and drainage system care technique.

Second phase (intervention) included implementation of infection control program based on the conceptual model of Comprehensive Unit-based Safety Program (CUSP) (6).

1. Engage: Explain why CAUTI prevention is important to all stakeholders and institutional managers in clear, concise and compelling way.
2. Educate: Share evidence supporting the interventions according to Healthcare Infection Control Practices Advisory Committee (HICPAC) Guideline for the Prevention of CAUTI (10) through training sessions for health care providers.

3. Execute: Design an intervention toolkit according to APIC Implementation Guide (10). Health care providers implemented the CAUTI bundle. It included: Appropriate Urinary Catheter Use, Proper Techniques for Urinary Catheter Insertion, and Proper Techniques for Urinary Catheter Maintenance.

4. Evaluate: Measure effectiveness of the intervention. Continue active electronic surveillance for CAUTI and calculate CDC National Healthcare Safety Network CAUTI Measures (11). Reassessment of health care providers' knowledge and practice about CAUTI and its prevention.

Data management:

1. Scoring of knowledge questionnaire:

Assessment of knowledge was divided to 5 sections: Infection control inside ICUs, Catheter associated urinary tract infection \& its prevention, Guidelines for urinary catheterization, Guidelines for urinary catheter and perineal care, Guidelines for urine bag and drainage system care (10 items).

Scoring system for knowledge items was as follows:

- $\quad$ Each correct answer took 1 degree.

- $\quad$ Each incorrect answer took zero.

Maximum score of the questionnaire was 71 . Total score of the whole questionnaire and each section is calculated as percentage. Knowledge level was calculated as follows:

- $\quad$ Bad knowledge: total score $<50 \%$

- $\quad$ Fair knowledge: total score $50-75 \%$

- Good knowledge: total score $>75 \%$

ii. Scoring of Performance observation checklist:

Performance observation checklist had 23 items divided to 3 sections:

Aseptic technique for urinary catheter insertion (11 items)

Urinary catheter and perineal care technique (4 items)

Urine bag and drainage system care technique (8 items) 
Scoring system for knowledge items was as follows:

- $\quad$ Each Well-done performance took 2 degrees.

- $\quad$ Each Incomplete performance took 1 degree.

- $\quad$ Each not done performance took zero. Maximum score of the checklist was 46. Total score of the whole checklist and each section is calculated as percentage. Practice level was calculated as follows:

- $\quad$ Bad Practice: total score $<50 \%$

- $\quad$ Fair Practice: total score $50-75 \%$

- Good Practice: total score $>75 \%$

iii. Statistical analysis:

The collected data was entered to and analyzed by computer using Statistical Package of Social Services version 24 (SPSS) (12).

Results were presented by tables and graphs. Continuous data was presented as mean, median, range and standard deviation. Qualitative data was presented as frequencies and proportions.

Pearson Chi square test $\left(\chi^{2}\right)$, fisher exact and Extended Mantel Hansel test $(\chi 2$ for linear trend) were used to analyze qualitative independent data. Student's t test (t) were used to analyze quantitative independent

McNemar test and Wilcoxon sign test were used to test paired data as appropriate (13).

In all the tests, $p$ value of $\leq 0.05$ was taken as significant.

\section{* Administrative design and Ethical considerations:}

1. Approval of Institutional Review Board (IRB) of Zagazig University, Faculty of medicine was taken after revision of study protocol.

2. An official permission from Zagazig University, Faculty of medicine was taken to intensive care units. Zagazig university Hospital was informed about the nature and steps of the study and written consent was taken from institutional managers.

3. An official permission from Central Unit of Infection Control in Zagazig university Hospital was taken to access and use electronic surveillance data.
4. The study health care providers were informed about the nature and the purpose of the study and verbal consent was taken before interview.

5. All health care providers' and patient's data were confidential.

\section{RESULTS}

Regarding demographic characteristics of resident physicians in the studied intensive care units (Table 1), mean age was $26.2 \pm 1.0$ years old. Almost two thirties were females. Mean of experience years in ICU was $2.1 \pm$ 0.9 . None of resident physicians in the studied intensive care units had training courses on infection control.

Regarding demographic characteristics of nurses in the studied intensive care units (Table, 2), mean age was $25.8 \pm 5.1$ years old. The majority were females. Almost two thirties had diplomate degree. Mean of experience years in ICU was $8.5 \pm 2.2$. Almost two thirties of nurses had attended previous training courses on infection control. Nurse/bed ratio was $1 / 2$ per shift.

There was a high statistical significant increase in knowledge of resident physicians about guidelines for prevention of CAUTI in the studied intensive care units after intervention $(\mathrm{P}<0.01)$. Before intervention, total knowledge level was "bad" in $45.0 \%$, "fair" in $40.0 \%$ and "good" in only $15.0 \%$ of resident physicians. After intervention, total knowledge level was "bad" in $30.0 \%$, "fair" in $35.0 \%$ and "good" in $35.0 \%$ of resident physicians (Figure 1).

The highest knowledge scores of resident physicians were for: CAUTI and its prevention (definition, risk factors, causative organisms, diagnosis, complications and management), followed by guidelines for urinary catheter and perineal care (frequency, steps, precautions). The lowest knowledge scores of resident physicians were for: Infection control inside ICUs (HAIs and prevention bundles), guidelines for urinary catheterization, guidelines for urine bag and drainage system care (frequency, steps, precautions).

There was a high statistical significant increase in knowledge of nurses about guidelines for prevention of CAUTI in the 
studied intensive care units after intervention ( $\mathrm{P}<0.01$ ). Before intervention, total knowledge level was "bad" in $38.0 \%$ and "fair" in $62.0 \%$ of nurses. After intervention, total knowledge level was "fair" in $68.0 \%$ and "good" in 32.0\% of nurses (Figure 2).

The highest knowledge scores of nurses were for: Guidelines for urine bag and drainage system care, followed by guidelines for urinary catheterization, and guidelines for urinary catheter and perineal care. The lowest knowledge scores of nurses were for: Infection control inside ICUs, and CAUTI and its prevention.

There was high statistical significant improvement in urinary catheterization practice in the studied intensive care units after intervention ( $\mathrm{P}<0.01)$. Urinary catheterization practice includes urinary catheter insertion, urinary catheter and perineal care, urine bag and drainage system. It was duty of ICUs' nurses. Before intervention, total practice level was "bad" in $20.0 \%$ and "fair" in $80.0 \%$ of nurses. After intervention, total practice level was "fair" in $54.0 \%$ and "good" in $46.0 \%$ of nurses (Figure 3 ). The highest practice scores were for urine bag and drainage system care technique. The lowest practice scores were for urinary catheter and perineal care technique, and technique of urinary catheter insertion.

The most noticed pitfalls during urinary catheter insertion were: defective aseptic technique, lack of perineal and peri-urethral cleaning before catheter insertion, unavailability of single-use lubricant gel, multiple-use gel was applied.

The most noticed pitfalls during urinary catheter and perineal care were: not done routinely in most patients, urinary catheters were not secured (not fixed to lower abdomen of male patients nor to upper medial thigh of female patients), urinary catheter flush to resolve obstructions, urinary bladder wash without appropriate indications, not changing urinary catheters after allowable usage period (one week for Foley and one month for silicone catheters).

The most noticed pitfalls during urine bag and drainage system care were defective aseptic technique, presence of obstructions/kinks in drainage system care, presence of dependent loop, absence of urine bag stand in some beds in emergency ICU.

Regarding demographic characteristics of patients (Table, 3 ), mean age was $37.3 \pm 11.4$ years, $61.0 \%$ were males, median length of stay was 16.0 days, median urinary catheter duration was 16.0 days, $62.0 \%$ were in emergency ICU.

There was a high statistical significant reduction in incidence of CAUTI after intervention (Figure 4). Before intervention, CAUTI incidence was 10.6 per 1000 urinary catheter days. While after intervention, CAUTI incidence significantly dropped to 5.4 per 1000 urinary catheter days. Risk of CAUTI before intervention was approximately twice that after intervention. The intervention reduced risk of CAUTI by $49.1 \%$.

Regarding isolated pathogens associated with reported CAUTI (Table 4), the most frequent isolated pathogens were Klebsiella spp. (31.4\%), followed by Candida albicans (21.4\%), Pseudomonas spp. (14.3\%) and E. coli $(12.9 \%)$. There was statistical significant increase in distribution of Candida albicans associated with reported CAUTI in the studied intensive care units after intervention. Candida albicans became the most frequent isolated pathogens associated with reported CAUTI because the intervention decreased all types of pathogens associated with CAUTI except for Candida albicans. 
Table (1): Demographic characteristics of resident physicians in the studied intensive care units

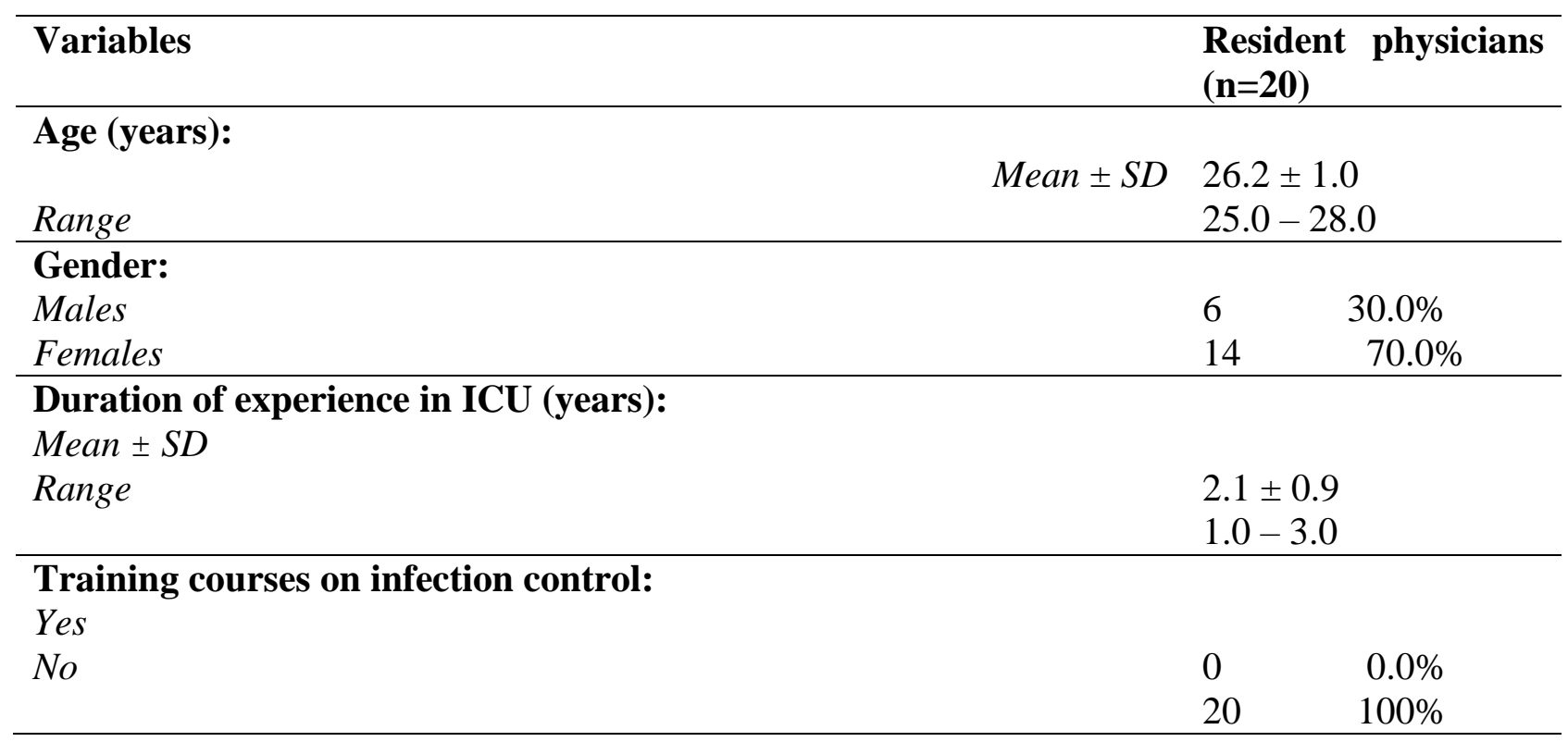

Table (2): Demographic characteristics of nurses in the studied intensive care units

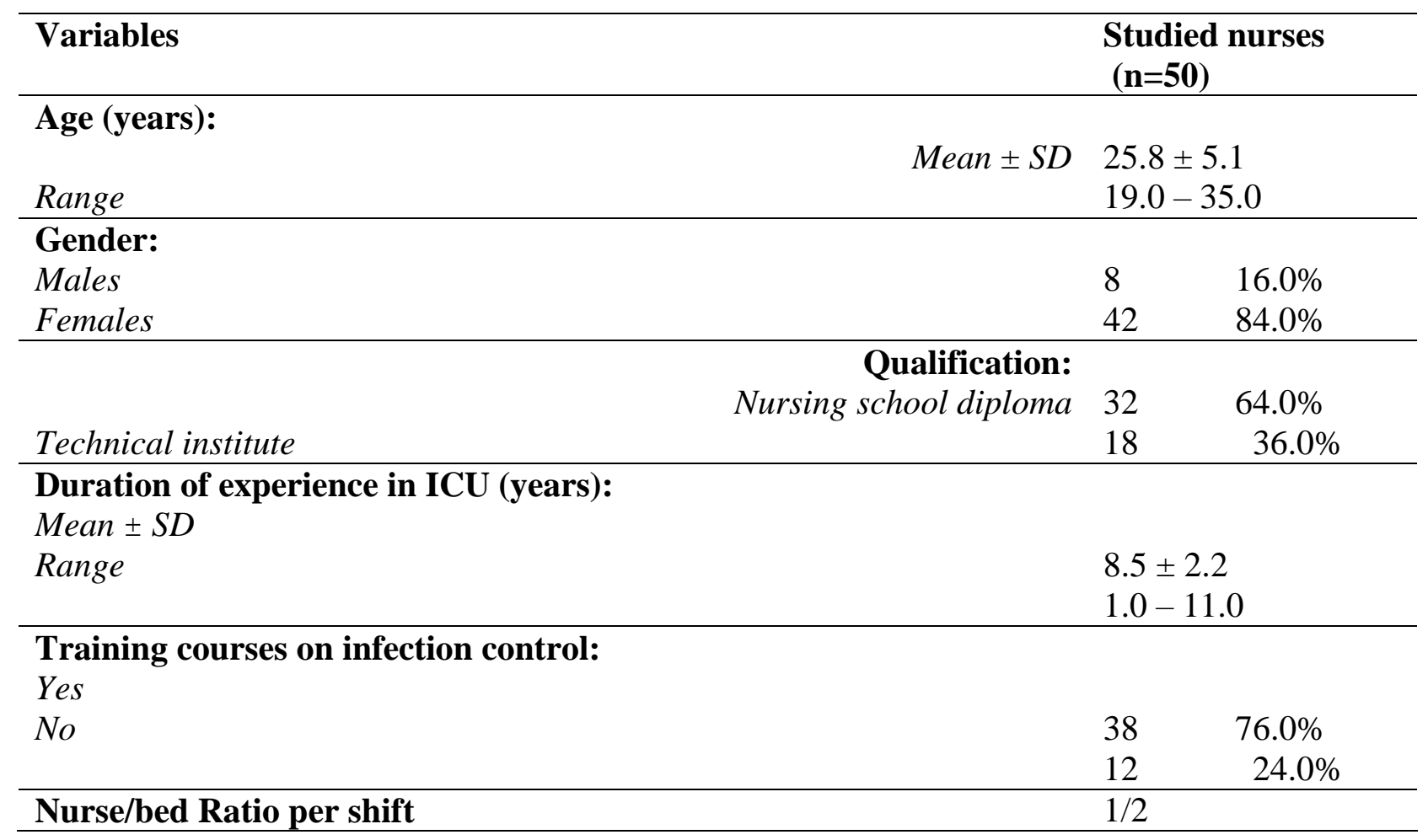




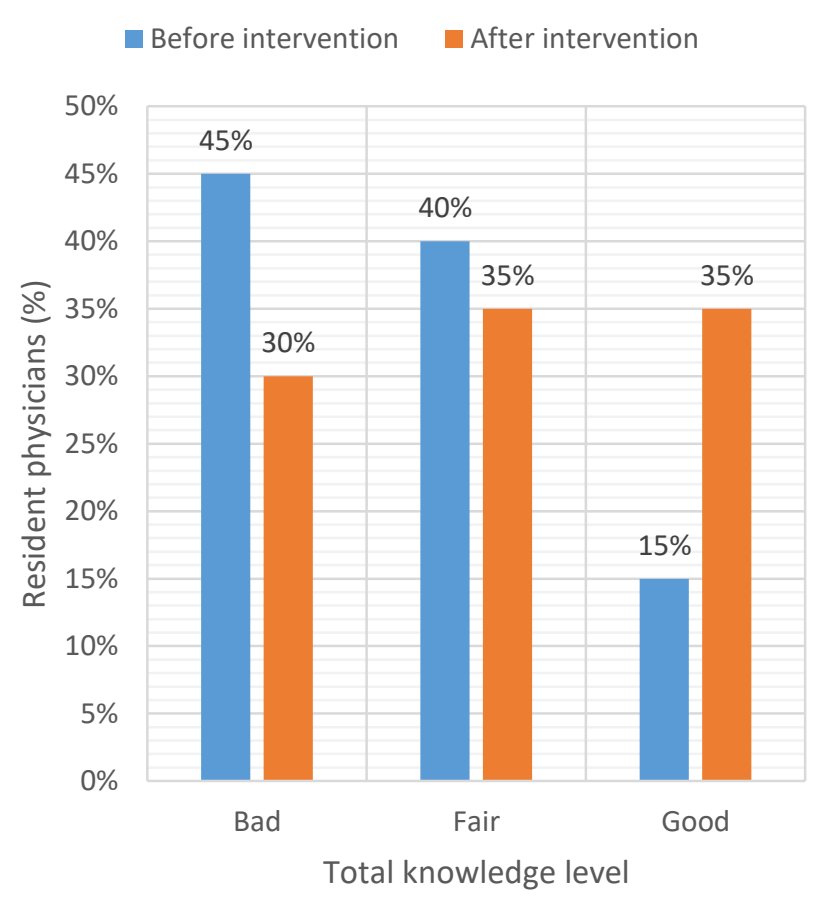

Figure (1): Total knowledge level of resident physicians in the studied intensive care units before and after intervention

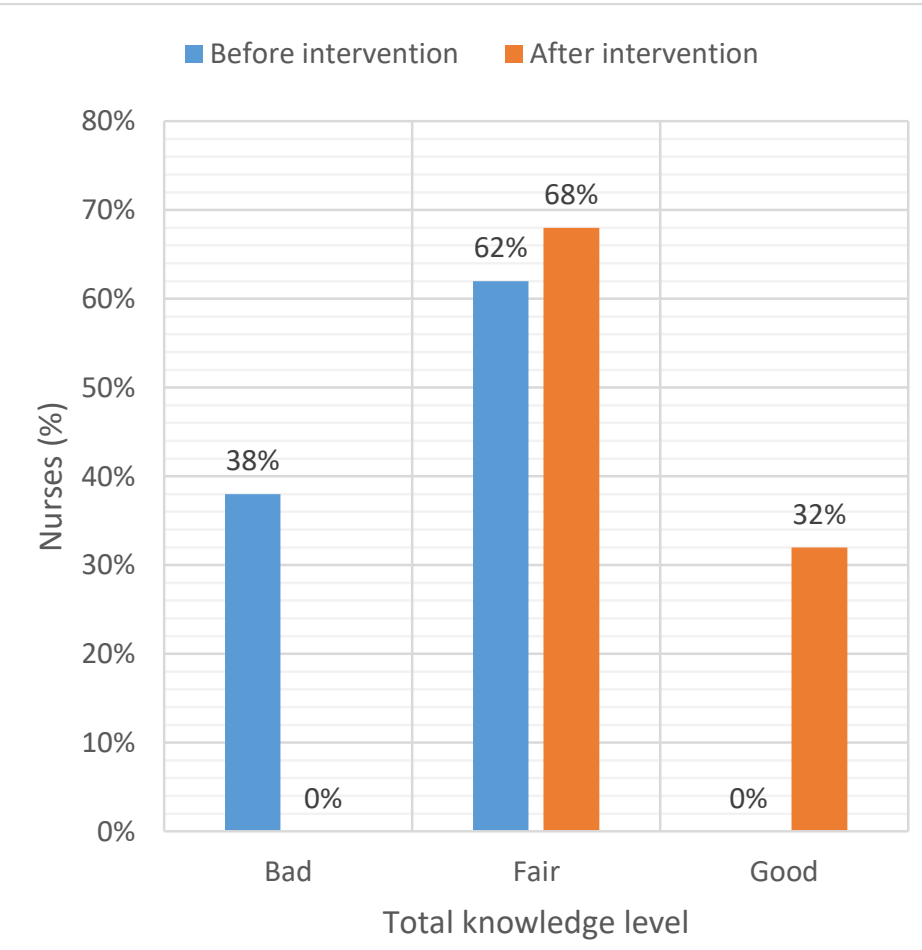

Figure (2): Total knowledge level of nurses in the studied intensive care units before and after intervention 


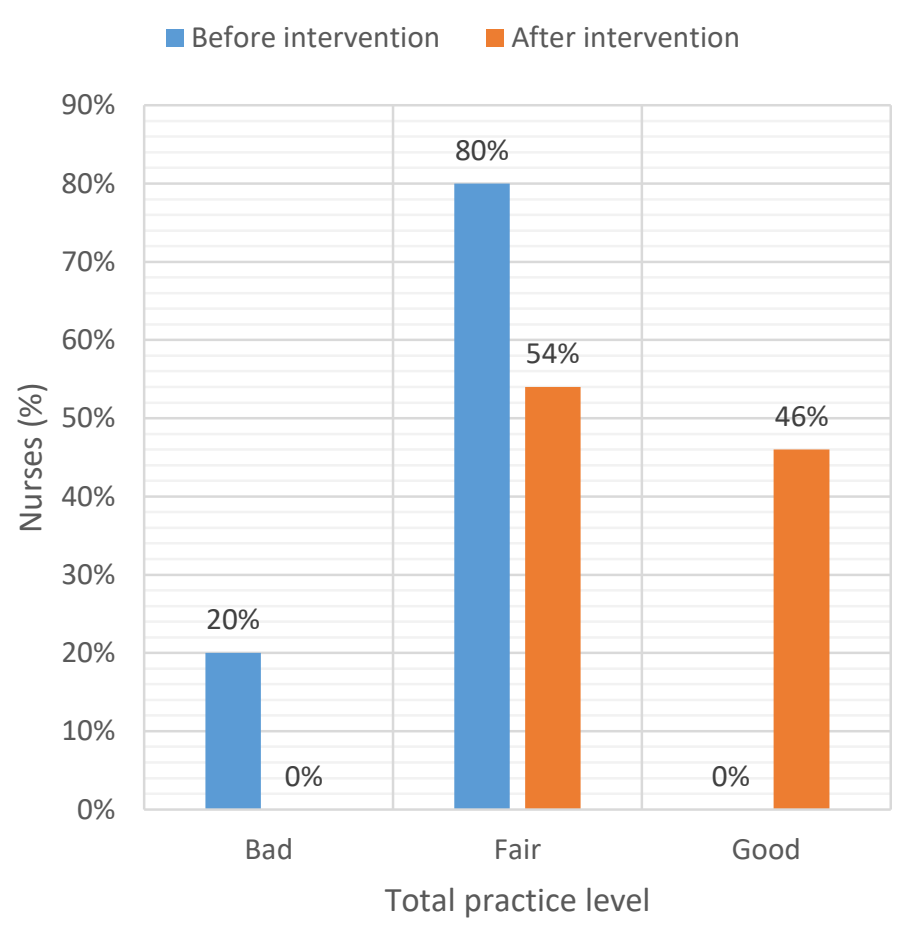

Figure (3): Total practice level of nurses in the studied intensive care units before and after intervention

Table (3): Demographic characteristics of patients in the studied intensive care units

\begin{tabular}{|c|c|c|}
\hline Variables & & $\begin{array}{l}\text { Studied patients } \\
(n=674)\end{array}$ \\
\hline \multicolumn{3}{|l|}{ Age (years): } \\
\hline Range & Mean $\pm S D$ & $\begin{array}{l}37.3 \pm 11.4 \\
1.0-65.0\end{array}$ \\
\hline \multicolumn{3}{|l|}{ Gender: } \\
\hline Males & & $61.0 \%$ \\
\hline Females & & $39.0 \%$ \\
\hline \multicolumn{3}{|c|}{ Length of stay (days): } \\
\hline Median & \multicolumn{2}{|r|}{16.0} \\
\hline Range & & $1.0-60.0$ \\
\hline \multicolumn{3}{|c|}{ Urinary catheter days: } \\
\hline Range & & $\begin{array}{l}16.0 \\
1.0-60.0\end{array}$ \\
\hline \multicolumn{3}{|l|}{ ICU Type: } \\
\hline Surgical ICU & & $38.0 \%$ \\
\hline Emergency ICU & & $62.0 \%$ \\
\hline
\end{tabular}




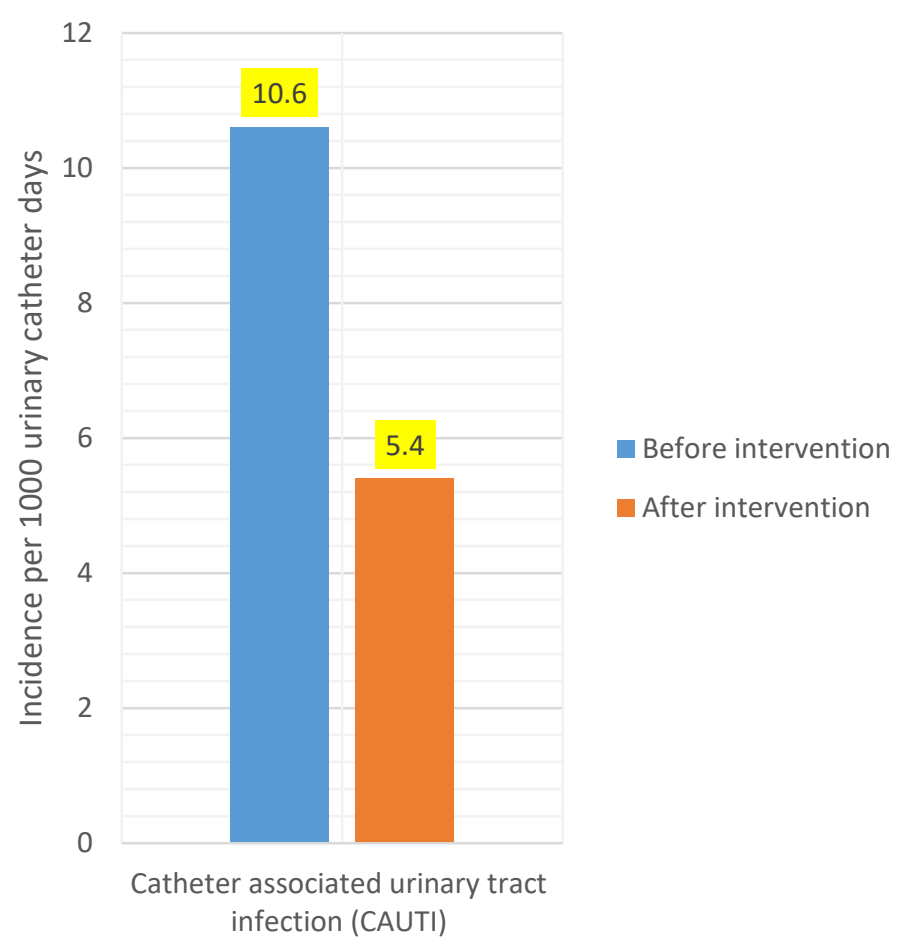

Figure (4): Incidence of Catheter associated urinary tract infection (CAUTI) in the studied intensive care units before and after intervention

Table (4): Distribution of isolated pathogens associated with reported CAUTI in the studied intensive care units

\begin{tabular}{|c|c|c|c|c|c|c|c|c|}
\hline \multirow[t]{2}{*}{ Isolated pathogens } & \multicolumn{2}{|c|}{$\begin{array}{l}\text { Total } \\
\text { infections } \\
(n=70)\end{array}$} & \multicolumn{2}{|c|}{$\begin{array}{l}\text { Before } \\
\text { intervention } \\
(n=48)\end{array}$} & \multicolumn{2}{|c|}{$\begin{array}{l}\text { After } \\
\text { intervention } \\
(n=22)\end{array}$} & \multirow[t]{2}{*}{$\chi^{2}$} & \multirow[t]{2}{*}{$\mathbf{P}$} \\
\hline & No & $\%$ & $\mathrm{No}$ & $\%$ & No & $\%$ & & \\
\hline Klebsiella spp. & 22 & 31.4 & 18 & 37.5 & 4 & 18.2 & 2.6 & 0.1 \\
\hline Candida albicans & 15 & 21.4 & 6 & 12.5 & 9 & 40.9 & 7.2 & $0.007 *$ \\
\hline Pseudomonas spp. & 10 & 14.3 & 6 & 12.5 & 4 & 18.2 & fisher & 0.7 \\
\hline E. coli & 9 & 12.9 & 7 & 14.6 & 2 & 9.1 & fisher & 0.2 \\
\hline Acinetobacter spp. & 7 & 10.0 & 6 & 12.5 & 1 & 4.6 & fisher & 0.4 \\
\hline Proteus spp. & 4 & 5.7 & 2 & 4.2 & 2 & 9.1 & fisher & 0.6 \\
\hline S. aureus & 3 & 4.3 & 3 & 6.3 & 0 & 0.0 & fisher & 0.5 \\
\hline
\end{tabular}

*Statistical significance

\section{DISCUSSION}

This study describes effect of implementation of infection control program on CAUTIs in ICUs at Zagazig university hospital. There was high statistical significant improvement in knowledge of both resident physicians and nurses about guidelines for prevention of catheter associated urinary tract infection in the studied intensive care units after intervention. Different studies have been done to assess the level of knowledge. In India, a study was done to assess the knowledge and attitude of health care providers about catheter indications and CAUTI prevention methods (14). The study found that nursing staff had a low level of knowledge regarding catheter care, and issues regarding urinary catheter indications and the much-needed preventive measures, but it is the healthcare providers' knowledge base which is lacking and needs improvement and education.

Anther Indian study, about knowledge regarding catheter care among staff nurses, 
appeared to show that almost half of staff nurses had adequate knowledge regarding catheter care (15). There was a lack of knowledge regarding practicing of measures such as cleaning around the catheter daily, glove use, and hand hygiene with catheter manipulation, not disconnecting the catheter from its bag, not routinely irrigating the catheter.

In Finland, a study concluded that, there is a huge gap in nurses' education of CAUTI (16). There was also a distinct lack of awareness amongst nurses and other healthcare professionals about the consequences of CAUTI. Catheters are frequently inserted for the wrong reasons, and the care and maintenance of catheters is often nonevidence based. They also discovered a lack of consistent documentation of catheter insertion and care.

In Pakistan, a study was done to assess infection control in the use of urethral catheter regarding knowledge and practice of nurses (17). Only $48 \%$ had adequate knowledge level and $50 \%$ had good practice about infection control in the use of urethral catheter. This study also indicated that nurses need to be educated and trained more on infection control in the use of urethral catheter and associated UTI.

In Rwanda, a study showed low levels of knowledge among nurses (knowledge level was not satisfactory in $64.5 \%$ of respondents) but no demographic factor was seen as a barrier to nurses' knowledge, attitude and practice towards the prevention of CAUTI (18).

In contrast to our study, in USA, a study found that physicians had relatively good knowledge regarding Foley catheter use, and most were aware of the changed CAUTI reimbursement policy (19).

There was high statistical significant improvement in urinary catheterization practice in the studied intensive care units after intervention. In Alexandria University hospitals (20), total practice level was unsatisfactory in $60.0 \%$ of ICUs' healthcare staff. There was lack of use of infection control measures e.g. handwashing and use of aseptic techniques during catheter insertion, especially if inserted outside of the ICUs. Most of CAUTI patients had their catheters inserted in the emergency department of the hospital, with limited knowledge and compliance to infection control precautions before and during catheter insertion.

In Iran, (21), total practice level was satisfactory in half of ICUs' healthcare staff. The most frequent pitfalls were: defective aseptic technique during catheter insertion and emptying urine bag, using multiple-use lubricant gel, antibiotic prescription before catheter insertion, lack of appropriate perineal care, drainage of urine bag into a common container for many patients.

In Taiwan, (22), For the elements of the insertion bundle, the compliance was the lowest for cleaning of the perineum, followed by hand hygiene. The overall compliance rates of the insertion bundle were $93.4 \%$. For the elements of the maintenance bundle, the compliance was the lowest for daily review of the need of a Foley catheter. The overall compliance rates of the maintenance bundle were $95.7 \%$. In USA, a study reported better compliance rate $(95.0 \%)$ with practice guidelines (23).

Studies that included implementation of infection control educational intervention, in Argentina (24), Brazil (25), Turkey (26), China (27) and Norway (28), total practice level of ICU staff significantly improved after intervention.

Incidence of CAUTI significantly decreased after intervention. Risk of CAUTI before intervention was approximately twice that after intervention. The intervention reduced risk of CAUTI by $49.1 \%$. Improved knowledge and practice of ICUs' staff contributed to reduction of CAUTI incidence. Organizational commitment from Infection Control Unit and ICUs' managers were facilitators for achieving that results.

In the sophisticated environment of ICUs, several factors might have contributed to the 
high device associated infections (DAI) rates identified in the Zagazig university hospital's ICUs. Being a major teaching referral hospital is an important risk factor. Several studies have found higher DAI rates in teaching hospitals compared with nonteaching hospitals (29). Funds and resources for infection control are limited and changing behavior of staff to promote safety practices is a long-term process. Nurse understaffing is at a critical level, and the low nurse/bed ratio might be related to the high DAI rates. Previous studies have linked understaffing with device-related infections in an outbreak setting (30). Nurse/bed ratio in this study was $1 / 2$ per shift which was insufficient according to WHO guidelines (30). This high ratio exposes nurses to work overload and intimidates quality of healthcare. Nurse/bed ratio was similar to that of Egyptian studies conducted at Zagazig university hospital (31), (32) Cairo university hospital (33), (34) and Alexandria university hospital (20). However, nurse/bed ratio was lower than that in some countries e.g. USA (35), (36) Germany (37), Turkey (26), Spain (38), Kuwait (39) and Saudi Arabia (40) where nurse/bed ratio was 1:1.

In comparison with the recognized international benchmarks, CAUTI incidence in our study was higher than that reported by: the National Healthcare Safety Network (NHSN) (1.5 per 1000 urinary catheter days), the International Nosocomial Infection Control Consortium (INICC) (7.1 per 1000 urinary catheter days), European Centre for Disease Prevention and Control (ECDC) (6.5 per 1000 urinary catheter days) and WHO report for High-resource countries (4.1 per 1000 urinary catheter days), while CAUTI incidence in our study was similar to that in WHO report for Low-resource countries (8.8 per 1000 urinary catheter days) (41).

As a device associated infection, CAUTI incidence varies widely between different countries according to healthcare quality, infection control infrastructure and resources. device associated infections rates in the ICUs of countries with limited resources are three to five times higher than rates in the ICUs of high-income countries, as reported from hospitals of the International Nosocomial Infection Control Consortium (INICC) (42). In addition, it varies according to duration and setting of study. Short-term studies are limited in reflecting the true incidence of CAUTI and are likely under-diagnose infections. Also, data from other healthcare settings can hardly be compared with finding in ICU with its own specific peculiarities. (30).

CAUTI incidence in this study was similar to studies conducted in the following countries: Turkey (43), Brazil, Colombia, Cuba, India, Macedonia, Mexico, Morocco, Peru, Philippines (44), Argentina (24) and Iran (45). CAUTI incidence in this study was lower than studies conducted in the following countries: In Egypt, incidence was 34.2 per 1000 urinary catheter days in Cairo university hospital (46) and 15.7 per 1000 catheter days in Alexandria university hospital (33). Compared to our study, their sample included patients with higher mean age, more females and higher length of stay in ICU. This explains their high CAUTI incidence. In Pakistan incidence was 16.4 per 1000 urinary catheter days (47). In Mongolia, incidence was 15.7 per 1000 urinary catheter days (48). In Mexico, incidence was 13.4 per 1000 urinary catheter days (49). In Lebanon, incidence was 13.1 per 1000 urinary catheter days (50).

CAUTI incidence in this study was higher than studies conducted in the following countries: In Germany, incidence was 0.68 per 1000 urinary catheter days (51). In India, incidence was 1.4 per 1000 urinary catheter days (52). In Korea, incidence was 1.9 per 1000 urinary catheter days (53). In china, incidence was 2.1 per 1000 urinary catheter days (54). In Cyprus, incidence was 2.7 per 1000 urinary catheter days (55). In Korea, incidence was 3.9 per 1000 urinary catheter days (56). In Spain, incidence was 4.2 per 1000 urinary catheter days (57). In USA, 
incidence was 4.3 per 1000 urinary catheter days (58). In Saudi Arabia, incidence was 4.4 per 1000 urinary catheter days (40). In Italy, incidence was 5.8 per 1000 urinary catheter days (59). In Taiwan, incidence was 6.5 (27) \& 3.9 (22) per 1000 urinary catheter days. Almost all of previously mentioned studies included patients with shorter length of stay in ICU. Prolonged length of stay in ICU is an important risk factor for CAUTI. It can be also a complication of HAIs. Also, their samples included both medical and surgical ICUs. Medical ICUs have less CAUTI risk than surgical ICUs (11).

The most frequent isolated pathogens were Klebsiella spp., followed by Candida albicans, Pseudomonas spp. and E. coli. There was statistical significant increase in distribution of Candida albicans associated with reported CAUTI in the studied intensive care units after intervention. Candida albicans became the most frequent isolated pathogens associated with reported CAUTI because the intervention decreased all types of pathogens associated with CAUTI except for Candida albicans. Candida albicans infections are tied with misuse of antibiotics and immunosuppression of patients (60). To control this type of infections, more interventions are required e.g. antibiotic stewardship.

In Egypt, at Alexandria university hospitals (20), the most frequent isolated organisms were Candida $(51.0 \%)$, gram negative bacteria $(33.5 \%)$ and gram positive bacteria $(15.4 \%)$.

In Turkey (43), the most frequent isolated organisms were Candida (44.9\%), Enterobacteriaceae $(24.9 \%)$ and Pseudomonas spp. $(12.5 \%)$.

In Spain (57), the most frequent isolated organisms were Escherichia coli (26\%), Candida (25\%) and Pseudomonas aeruginosa $(10 \%)$.

In Korea (56), the most frequent isolated organisms were Candida albicans (40\%), Escherichia coli (38\%) and Enterococcus faecalis (15\%).
In Philippines (52), the most frequent isolated organisms were Candida albicans (30\%), Escherichia coli (12\%), Acinetobacter spp. (12\%) and Klebsiella spp. (12\%).

In Brazil (25), Monomicrobial infection was 96\% while Polymicrobial infection was $4 \%$. The most frequent isolated organisms were Pseudomonas aeruginosa (20.7\%), Klebsiella pneumoniae (13.2\%), Escherichia coli (11.6\%), Enterococcus faecalis (8.3\%) and Candida albicans (7.4\%).

\section{Conclusion}

At Zagazig university hospitals' ICUs, implementation of infection control program on CAUTI was noticed to be associated with improvement in healthcare providers knowledge and practice and decrease in CAUTI incidence. Sustainability is required to maintain that improvement. So. It is recommended to keep continuous training of ICU staff and upgrade ICU protocols according to recent guidelines.

\section{REFERENCES}

1. Centers for Disease Control and Prevention. Urinary Tract Infection (Catheter-Associated Urinary Tract Infection [CAUTI] and Non-CatheterAssociated Urinary Tract Infection [UTI]) and Other Urinary System Infection [USI]) Events. In: 2016 NHSN Patient Safety Component Manual [Internet]. 2016. p. 116. Available from: http://www.cdc.gov/nhsn/pdfs/pscmanual/ 7psccauticurrent.pdf

2. Boev C, Kiss E. Hospital-Acquired Infections: Current Trends and Prevention. Vol. 29, Critical Care Nursing Clinics of North America. 2017. p. 51-65.

3. Leone C, Babcock H. Catheter associated urinary tract infection algorithm performance for ICU and non-ICU surveillance. Am J Infect Control [Internet]. 2016;44(6):S50-1. Available from:

http://www.embase.com/search/results?sub action=viewrecord\&from=export\&id=L72 334371\%5Cnhttp://dx.doi.org/10.1016/j.aji c.2016.04.044

4. Tedja R, Wentink J, O'Horo JC, Thompson R, Sampathkumar P. CatheterAssociated Urinary Tract Infections in Intensive Care Unit Patients. Infect Control Hosp Epidemiol [Internet]. 
2015;36(11):1330-4. Available from: http://www.ncbi.nlm.nih.gov/pubmed/261 90686

5. Shuman EK, Chenoweth CE. Recognition and prevention of healthcare-associated urinary tract infections in the intensive care unit. Crit Care Med [Internet]. 2010;38:S373-S379

10.1097/CCM.0b013e3181e6ce8f.

Available

from:

http://journals.lww.com/ccmjournal/Fullte

xt/2010/08001/Recognition_and_preventio n_of.13.aspx

6. AHRQ. Comprehensive unit-based safety program (CUSP) [Internet]. Definitions of Quality Indicators, Version 1.3. 2015. Available from: http://www.ahrq.gov/professionals/qualitypatient-safety/cusp/index.html

7. Huang W-C, Wann S-R, Lin S-L, Kunin CM, Kung M-H, Lin C-H, et al. CatheterAssociated Urinary Tract Infections in Intensive Care Units Can Be Reduced by Prompting Physicians to Remove Unnecessary Catheters. Infect Control Hosp Epidemiol [Internet]. 2004;25(11):974-8. Available from: https://www.cambridge.org/core/product/i dentifier/S0195941700080966/type/journal _article

8. Centers for Disease Control and Prevention. Introduction to Epi Info ${ }^{\mathrm{TM}} 7$ Using Epi Info ${ }^{\mathrm{TM}}$ [Internet]. Epi Info. 2015. p. 1-2. Available from: http://wwwn.cdc.gov/epiinfo/

9. CDC. THE NHSN STANDARDIZED UTILIZATION RATIO (SUR) Finding and Interpreting SURs in NHSN. 2018 [cited 2018 Jun 26]; Available from: https://www.cdc.gov/nhsn/pdfs/ps-

analysis-resources/nhsn-sur-guide-508.pdf

10. APIC releases updated Guide to Preventing Catheter-Associated Urinary Tract Infections. Am J Infect Control. 2014;42(8):819.

11. CDC, Oid, Ncezid, DHQP. National Healthcare Safety Network (NHSN) Patient Safety Component Manual. 2018 [cited 2018 Mar 24]; Available from: https://www.cdc.gov/nhsn/pdfs/pscmanual/ pcsmanual_current.pdf

12. IBM Corp. Released. IBM SPSS Statistics for Windows, Version 24.0. 2016. 2016;

13. Kirkwood B, Sterne J. Medical statistics. Med Stat [Internet]. 2003;513. Available from:

http://scholar.google.com/scholar?hl=en\&
btnG=Search\&q=intitle:Medical+statistics \#2

14. Jain M, Dogra V, Mishra B, Thakur A, Loomba P. Knowledge and attitude of doctors and nurses regarding indication for catheterization and prevention of catheterassociated urinary tract infection in a tertiary care hospital. Indian J Crit Care Med [Internet]. 2015 Feb [cited 2018 Jun 18];19(2):76. Available from: http://www.ncbi.nlm.nih.gov/pubmed/257 22548

15. Prasanna K, Radhika M. Knowledge regarding Catheter care among Staff Nurses. Int J Appl Res [Internet]. 2015 [cited 2018 Jun 18];1(8):182-6. Available from: www.allresearchjournal.com

16. Banks R, Willmann H. Nursing Interventions Aimed at Reducing the Incidence of Hospital Acquired CatheterAssociated Urinary Tract Infections. 2016 [cited 2018 Jun 7]; Available from: https://www.theseus.fi/bitstream/handle/10 024/112505/Banks_Hannah.pdf?sequence $=1$

17. Shah M, Wahab F, Ullah F, Gul U, Aziz A, Ullah Z. Infection Control in the Use of Urethral Catheter: Knowledge and Practises of Nurses. Am J Adv Drug Deliv [Internet]. 2017 [cited 2018 Jun 18];05(01). Available from: http://www.imedpub.com/advanced-drugdelivery/

18. Mukakamanzi J. Knowledge, attitude and practice of nurses towards the prevention of catheter associated urinary tract infection in selected referral hospitals in Rwanda.. 2017 [cited 2018 Jun 18]; Available from: http://dr.ur.ac.rw/bitstream/handle/123456 789/324/MUKAKAMANZI

Jacqueline.pdf?sequence $=1 \&$ is 1 llowed $=y$

19. Drekonja DM, Kuskowski MA, Johnson JR. Foley catheter practices and knowledge among Minnesota physicians. Am J Infect Control [Internet]. 2010 Nov 1 [cited 2018 Jun 21];38(9):694-700. Available from: http://www.ncbi.nlm.nih.gov/pubmed/206 05268

20. Talaat M, Hafez S, Saied T, Elfeky R, ElShoubary W, Pimentel G. Surveillance of catheter-associated urinary tract infection in 4 intensive care units at Alexandria university hospitals in Egypt. Am J Infect Control. 2010;38(3):222-8.

21. Taleschian-Tabrizi N, Farhadi F, Madani 
N, Mokhtarkhani M, Kolahdouzan K, Hajebrahimi S. Compliance With Guideline Statements for Urethral Catheterization in an Iranian Teaching Hospital. Int $\mathbf{J}$ Heal Policy Manag [Internet]. 2015 Jul 14 [cited 2018 May 29];4(12):805-11. Available from: http://ijhpm.com/article_3056_616.html

22. Lai C-C, Lee C-M, Chiang H-T, Hung C$\mathrm{T}$, Chen Y-C, Su L-H, et al. Implementation of a national bundle care program to reduce catheter-associated urinary tract infection in high-risk units of hospitals in Taiwan. J Microbiol Immunol Infect [Internet]. 2017 Aug [cited 2018 May 26];50(4):464-70. Available from: http://www.ncbi.nlm.nih.gov/pubmed/287 11430

23. Conway LJ, Pogorzelska M, Larson E, Stone PW. Adoption of policies to prevent catheter-associated urinary tract infections in United States intensive care units. [Internet]. Vol. 40, Am J Infect Control. 2012. p. 705-10. Available from: http://eutils.ncbi.nlm.nih.gov/entrez/eutils/ elink.fcgi?dbfrom=pubmed\&amp;id=2231 7857\&amp;retmode=ref\&amp;cmd=prlink $\mathrm{s}$

24. Rosenthal VD. Device-associated nosocomial infections in limited-resources countries: Findings of the International Nosocomial Infection Control Consortium (INICC). Am J Infect Control. 2008;36(10).

25. Marra AR, Sampaio Camargo TZ, Gonçalves P, Sogayar AMCB, Moura DF, Guastelli LR, et al. Preventing catheterassociated urinary tract infection in the zero-tolerance era. Am J Infect Control [Internet]. 2011 Dec [cited 2018 May 25];39(10):817-22. Available from: http://www.ncbi.nlm.nih.gov/pubmed/217 04427

26. Alp E, Altun D, Cevahir F, Ersoy S, Cakir $\mathrm{O}$, McLaws ML. Evaluation of the effectiveness of an infection control program in adult intensive care units: a report from a middle-income country. Am J Infect Control. 2014;42(10):1056-61.

27. Chiu CF, Liu TY, Huang CT, Lin SY, Chen TC. Reducing catheter-associated urinary tract infection density in intensive care unit in a regional hospital. J Microbiol Immunol Infect [Internet]. 2015;1):S157. Available from: http://bf4dv7zn3u.search.serialssolutions.c om.myaccess.library.utoronto.ca/?url_ver=
Z39.88-

2004\&rft_val_fmt=info:ofi/fmt:kev:mtx:jo urnal\&rfr_id=info:sid/Ovid:emed17\&rft.g enre=article\&rft_id=info:doi/\&rft_id=info: $\mathrm{pmid} / \& \mathrm{rft}$.issn=1684-

$1182 \&$ rft. volume $=48 \&$ rft.

28. Holte HH, Underland V, Hafstad E. Systematic Reviews on Preventing Catheter-Associated Urinary Tract Infection [Internet]. Systematic Reviews on Preventing Catheter-Associated Urinary Tract Infection. 2016. Available from: http://www.ncbi.nlm.nih.gov/pubmed/295 53654

29. Birgand G, Johansson A, Szilagyi E, Lucet J-C. Overcoming the obstacles of implementing infection prevention and control guidelines. Clin Microbiol Infect [Internet]. 2015 Dec 1 [cited 2018 Jun 2];21(12):1067-71. Available from: https://www.sciencedirect.com/science/arti cle/pii/S1198743X15008204

30. World Health Organization (Who). Report on the Burden of Endemic Health CareAssociated Infection Worldwide. WHO Libr Cat Data [Internet]. 2011 [cited 2018 May 25];40. Available from: http://www.

31. Selim S, Abo El-Seoud A, Aboserea MM, Abd El-razik GM. An interventional study for reducing Ventilator Associated Pneumonia in Surgical Intensive Care Unit, Zagazig University Hospitals. IntJCurrMicrobiolAppSci Int $\mathrm{J}$ Curr Microbiol Appl Sci J IntJCurrMicrobiolAppSci [Internet]. 2016 [cited 2018 Apr 2];5(52):202-14. Available from: http://dx.doi.org/10.20546/ijcmas.2016.50 2.023

32. $\mathrm{Nm} \mathrm{A,} \mathrm{Hm} \mathrm{B,} \mathrm{Sa} \mathrm{B,} \mathrm{Ae} \mathrm{A,} \mathrm{Dm} \mathrm{A.}$ Methicillin-resisitent Staphylococcus aureas: An interventional study among health care workers of surgical ICU at Zagazig University Hospital, Egypt. Egypt J Occup Med [Internet]. 2017 [cited 2018 May 2];41(1):97-113. Available from: http://ejom.journals.ekb.eg/article_964_d8f 59bd4aa6b7eb19940552399a40716.pdf

33. El-Kholy A, Saied T, Gaber M, Younan MA, Haleim MMA, El-Sayed $\mathrm{H}$, et al. Device-associated nosocomial infection rates in intensive care units at Cairo University hospitals: First step toward initiating surveillance programs in a resource-limited country. Am J Infect Control. 2012;40(6).

34. Abdel-Hakeim E, Hamza A. The Effect of 
Implementing UrinaryCatheter Care Bundle on The Prevention of CatheterAssociated Urinary Tract Infections. IOSR J Nurs Heal Sci [Internet]. 2018 [cited 2018 Jun 3];7(1):2320-1940. Available from: www.iosrjournals.org

35. Connor BT. Exploring Factors Associated with Nurses' Adoption of an EvidenceBased Practice to Reduce CatheterAssociated Urinary Tract Infections. Vol. Ph.D., Exploring Factors Associated With Nurses' Adoption of an Evidence-based Practice to Reduce Catheter-associated Urinary Tract Infections. 2011.

36. Carberry GL, Hale M, Watters JM, Sherry $S$, Murray K. Enhanced Infection Preventionist Presence in a Trauma Intensive Care Unit Significantly Decreased Urinary Catheter Utilization Rates. Am J Infect Control [Internet]. 2011;39(5):E146-7. Available from: http://linkinghub.elsevier.com/retrieve/pii/ S0196655311006146

37. Gastmeier P, Behnke M, Schwab F, Geffers C. Benchmarking of urinary tract infection rates: Experiences from the intensive care unit component of the German national nosocomial infections surveillance system. J Hosp Infect. 2011;78(1):41-4.

38. Ternavasio-de la Vega HG, Barbosa Ventura A, Castaño-Romero F, Sauchelli FD, Prolo Acosta A, Rodríguez Alcázar FJ, et al. Assessment of a multi-modal intervention for the prevention of catheterassociated urinary tract infections. J Hosp Infect [Internet]. 2016;94(2):175-81. Available from: http://linkinghub.elsevier.com/retrieve/pii/ S0195670116302626

39. Al-Mousa HH, Omar AA, Rosenthal VD, Salama MF, Aly NY, El-Dossoky Noweir $\mathrm{M}$, et al. Device-associated infection rates, bacterial resistance, length of stay, and mortality in Kuwait: International Nosocomial Infection Consortium findings. Am J Infect Control. 2016;

40. Gaid E, Assiri A, McNabb S, Banjar W. Device-associated nosocomial infection in general hospitals, Kingdom of Saudi Arabia, 2013-2016. J Epidemiol Glob Health [Internet]. 2018 Mar 1 [cited 2018 May 25];7:S35-40. Available from: https://www.sciencedirect.com/science/arti cle/pii/S2210600617302265?via\%3Dihub

41. El-Saed A, Balkhy HH, Weber DJ. Benchmarking local healthcare-associated infections: Available benchmarks and interpretation challenges. J Infect Public Health [Internet]. 2013 [cited 2018 May 25];6:323-30. Available from: http://dx.doi.org/10.1016/j.jiph.2013.05.00 1

42. Rosenthal VD, Maki DG, Mehta Y, Leblebicioglu H, Memish ZA, Al-Mousa $\mathrm{HH}$, et al. International Nosocomial Infection Control Consortiu (INICC) report, data summary of 43 countries for 2007-2012. Device-associated module[J]. Am J Infect Control [Internet]. 2014;42(9):942-56. Available from: http://dx.doi.org/10.1016/j.ajic.2014.05.02 9

43. Leblebicioglu H, Rosenthal VD, Arikan ÖA, Özgültekin A, Yalcin AN, Koksal I, et al. Device-associated hospital-acquired infection rates in Turkish intensive care units. Findings of the International Nosocomial Infection Control Consortium (INICC). J Hosp Infect. 2007;65(3):251-7.

44. Rosenthal VD, Epidemiology H, Diseases I, Nosocomial I. Effectiveness of Outcome and Process Surveillance for Reducing Urinary Tract Infection Rates in 42 ICUs from 11 Countries. Findings of the International Nosocomial Infection Control Consortium ( INICC). Am J Infect Control [Internet]. 2007 Jun 1 [cited 2018 May 24];36(5):2007-8. Available from: http://linkinghub.elsevier.com/retrieve/pii/ S0196655308003957

45. Jahani-Sherafat S, Razaghi M, Rosenthal VD, Tajeddin E, Seyedjavadi S, Rashidan $\mathrm{M}$, et al. Device-associated infection rates and bacterial resistance in six academic teaching hospitals of Iran: Findings from the International Nocosomial Infection Control Consortium (INICC). J Infect Public Health [Internet]. 2015 Nov [cited 2018 May 25];8(6):553-61. Available from:

http://www.ncbi.nlm.nih.gov/pubmed/260 27477

46. Rasslan O, Seliem ZS, Ghazi IA, El Sabour MA, El Kholy AA, Sadeq FM, et al. Device-associated infection rates in adult and pediatric intensive care units of hospitals in Egypt. International Nosocomial Infection Control Consortium (INICC) findings. J Infect Public Health [Internet]. 2012 Dec [cited 2018 May 25];5(6):394-402. Available from: http://www.ncbi.nlm.nih.gov/pubmed/232 87610 
47. Sabir N, Ikram A, Zaman G, Satti L, Gardezi A, Ahmed A, et al. Bacterial biofilm-based catheter-associated urinary tract infections: Causative pathogens and antibiotic resistance. Am J Infect Control [Internet]. 2017 Oct 1 [cited 2018 May 25];45(10):1101-5. Available from: http://www.ncbi.nlm.nih.gov/pubmed/286 29757

48. Ider BE, Baatar O, Rosenthal VD, Khuderchuluun C, Baasanjav B, Donkhim $\mathrm{C}$, et al. Multicenter study of deviceassociated infection rates in hospitals of Mongolia: Findings of the International Nosocomial Infection Control Consortium (INICC). Am J Infect Control. 2016;

49. Ramirez Barba EJ, Rosenthal VD, Higuera F, Oropeza MS, Hernández HT, López MS, et al. Device-associated nosocomial infection rates in intensive care units in four Mexican public hospitals. Am J Infect Control [Internet]. 2006 May [cited 2018 May 25];34(4):244-7. Available from: http://www.ncbi.nlm.nih.gov/pubmed/166 79185

50. Kanj SS, Zahreddine N, Rosenthal VD, Alamuddin L, Kanafani Z, Molaeb B. Impact of a multidimensional infection control approach on catheter-associated urinary tract infection rates in an adult intensive care unit in Lebanon: International Nosocomial Infection Control Consortium (INICC) findings. Int J Infect Dis [Internet]. 2013 Sep [cited 2018 May 26];17(9):e686-90. Available from: http://www.ncbi.nlm.nih.gov/pubmed/234 90089

51. Gastmeier P, Behnke M, Schwab F, Geffers C. Benchmarking of urinary tract infection rates: experiences from the intensive care unit component of the German national nosocomial infections surveillance system. J Hosp Infect [Internet]. 2011 May 1 [cited 2018 May 24];78(1):41-4. Available from: http://www.ncbi.nlm.nih.gov/pubmed/214 81490

52. Navoa-Ng JA, Berba R, Galapia YA, Rosenthal VD, Villanueva VD, Tolentino $\mathrm{V}$, et al. Device-associated infections rates in adult, pediatric, and neonatal intensive care units of hospitals in the Philippines: International Nosocomial Infection Control Consortium (INICC) findings. Am J Infect Control [Internet]. 2011 [cited 2018 May 24];39:548-54. Available from: http://www.inicc.org/media/docs/2011-
AJIC-HAI_in_Philippines.pdf

53. Choi JY, Kwak YG, Yoo H, Lee S-O, Kim $\mathrm{HB}$, Han SH, et al. Trends in the incidence rate of device-associated infections in intensive care units after the establishment of the Korean Nosocomial Infections Surveillance System. J Hosp Infect [Internet]. 2015 Sep [cited 2018 May 25];91(1):28-34. Available from: http://www.ncbi.nlm.nih.gov/pubmed/261 49593

54. Li Y, Cao X, Ge H, Jiang Y, Zhou H, Zheng W. Targeted surveillance of nosocomial infection in intensive care units of 176 hospitals in Jiangsu province, China. J Hosp Infect [Internet]. 2018 May 1 [cited 2018 May 25];99(1):36-41. Available from: https://www.sciencedirect.com/science/arti cle/pii/S0195670117305492

55. Iordanou $S, \quad$ Middleton $N$, Papathanassoglou E, Raftopoulos V. Surveillance of device associated infections and mortality in a major intensive care unit in the Republic of Cyprus. BMC Infect Dis [Internet]. 2017 [cited 2018 May 25];17(1). Available from:

https://bmcinfectdis.biomedcentral.com/tra ck/pdf/10.1186/s12879-017-2704-2

56. Kwak YG, Lee S-O, Kim HY, Kim YK, Park ES, Jin HY, et al. Risk factors for device-associated infection related to organisational characteristics of intensive care units: findings from the Korean Nosocomial Infections Surveillance System. J Hosp Infect [Internet]. $2010 \mathrm{Jul}$ [cited 2018 May 24];75(3):195-9. Available from: http://www.ncbi.nlm.nih.gov/pubmed/204 34798

57. Álvarez-Lerma F, Gracia-Arnillas MP, Palomar M, Olaechea P, Insausti J, LópezPueyo MJ, et al. Infección urinaria relacionada con sonda uretral en pacientes críticos ingresados en UCI. Datos descriptivos del estudio ENVIN-UCI. Med Intensiva [Internet]. 2013 Mar [cited 2018 May 25];37(2):75-82. Available from: http://www.ncbi.nlm.nih.gov/pubmed/225 79562

58. Smith H, Brooks JE, Leaptrot D, AllenBridson K, Anttila A, Gross C, et al. Health care-associated infections studies project: An American Journal of Infection Control and National Healthcare Safety Network data quality collaboration. Am J 
Infect Control. 2017;45(6):612-4.

59. Marigliano A, Barbadoro P, Pennacchietti L, D'Errico MM, Prospero E, CAUTI Working Collaborative Group. Active training and surveillance: 2 good friends to reduce urinary catheterization rate. Am $\mathbf{J}$ Infect Control [Internet]. 2012 Oct 1 [cited 2018 May 24];40(8):692-5. Available from:

http://www.ncbi.nlm.nih.gov/pubmed/226
32823

60. Behzadi P, Behzadi E, Yazdanbod H, Aghapour R, Akbari Cheshmeh M, Salehian Omran D. Urinary Tract Infections Associated with Candida albicans. Maedica (Buchar) [Internet]. 2010 Dec [cited 2018 Jun 1];5(4):277-9. Available from: http://www.ncbi.nlm.nih.gov/pubmed/219 77170 